\title{
Binding of phospholipids to the phosphatidylinositol transfer protein from bovine brain as studied by steady-state and time-resolved fluorescence spectroscopy
}

\author{
P.A. Van Paridon ${ }^{a}$, A.J.W.G. Visser ${ }^{b}$ and K.W.A. Wirtz ${ }^{a}$ \\ ${ }^{a}$ Laboratory of Biochemistry, State University of Utrecht, Transitorium MI, Padualaan 8, NL-3584 CH Utrecht \\ and ${ }^{b}$ Department of Biochemistry, Agricultural University, De Dreijen 11, 6703 BC Wageningen (The Netherlands)
}

(Received 2 October 1986)

Key words: Phosphatidylinositol transfer protein; Phospholipid binding; Fluorescence spectroscopy; Time-resolved fluorescence spectroscopy; (Bovine brain)

The phosphatidylinositol transfer protein isolated from brain, liver, heart and platelets was found to be present in two subforms which could be distinguished on the basis of the isoelectric points. In this study we have demonstrated that the two subforms isolated from bovine brain are due to the presence of either phosphatidylinositol or phosphatidylcholine in the lipid binding site of the protein. The transfer protein accommodates one phosphatidylinositol molecule in the binding site. The binding site for the $s n-2$ fatty acyl chain was investigated by incorporating in the transfer protein either phosphatidylinositol or phosphatidylcholine carrying a parinaroyl-chain attached at the $s n-2$ position. Time-resolved fluorescence spectroscopy revealed that the $s n-2$ fatty acyl chains for both phospholipids in the lipid-protein complex were completely immobilized (i.e., rotational correlation times of $17.4 \mathrm{~ns}$ for phosphatidylcholine and $16.3 \mathrm{~ns}$ for phosphatidylinositol). The similarity in correlation times suggests that the $s n-2$ fatty acyl chains of both phospholipids are accommodated in the same hydrophobic binding site of the protein.

\section{Introduction}

The phosphatidylinositol (PI) transfer protein belongs to a group of soluble cytosolic proteins which presumably play a role in the transport of phospholipid molecules between intracellular organelles [1,2]. As a carrier this protein preferentially transfers PI, yet it will accept phosphatidylcholine (PC) whenever it interacts with a membrane that lacks or is deficient in PI [3-6]. The PI-transfer protein has been purified from a variety of tissues, including bovine brain [7], bovine heart [5], rat liver [8], yeast [9] and blood platelets [10]. In most of these purifications two subforms of the

\footnotetext{
Correspondence: P.A. van Paridon, Laboratory of Biochemistry, State University of Utrecht, Transitorium III, Padualaan 8, NL-3584 CH Utrecht, The Netherlands
}

protein (i.e., PI-transfer protein I and II) were identified with as main feature a difference in isoelectric point. Despite several attempts, the molecular basis for this difference has not been elucidated $[7,5,11]$.

In a recent study [6] fluorescent analogs of PI and PC carrying a parinaroyl chain at the $s n-2-$ position, were used to investigate their binding to the PI-transfer protein. It was demonstrated that the binding of PI was much more efficient than that of PC and that PI and PC could not be bound simultaneously. Previously it was proposed that the PI-transfer protein may have specific recognition sites for the phosphorylinositol and the phosphorylcholine headgroups, yet that it shares a common binding site for the fatty acyl chains [5]. We have followed up on this hypothesis by investigating the binding of parinaroyl-PI and parinaroyl-PC by use of time-resolved fluores- 
cence spectroscopy. This technique allows one to compare fluorescence lifeitmes, which are very sensitive to changes in environment [12], as well as fluorescence anisotropy decays which are a measure of acyl chain motion [13]. In a similar study on the binding of 1-parinaroyl-PC and 2parinaroyl-PC to the PC-transfer protein from bovine liver it was demonstrated that each acyl chain was completely immobilized on the protein thereby occupying different binding sites [14].

Here we will show that the different isoelectric points of PI-transfer protein I and II reflect the binding of either PI or PC and that both subforms have the same preference for PI over PC. In addition, data will be shown to suggest that the 2-parinaroyl chain of PI and PC are accommodated in a hydrophobic binding site on the transfer protein. From the different quantum yields and average fluorescence lifetimes, we infer that the chromophore of each lipid experiences a different local environment.

\section{Materials and Methods}

Phospholipids. Egg yolk PC, type IIIE and PA were purchased from Sigma. Yeast PI was prepared from autolysed baker's yeast [15] and purified as described elsewhere [16]. 2-Parinaroyl-PC was synthesized from PC and cis-parinaric acid (Molecular Probes, Junction City, Oregon) according to Somerharju et al. [17], parinaroyl-PI was prepared as described $[16,18]$. $\left[{ }^{14} \mathrm{C}\right] \mathrm{PC}$ (spec. act. $58.5 \mathrm{Ci} / \mathrm{mol}$ ) was prepared from egg-yolk PC by demethylation and remethylation with $\left[{ }^{14} \mathrm{C}\right]$ methyliodide [19], and $\left[{ }^{3} \mathrm{H}\right] \mathrm{PI}$ (spec. act. $1.8 \mathrm{Ci} / \mathrm{mol}$ ) was prepared by base exchange of $\left[{ }^{3} \mathrm{H}\right]$ myo-inositol in rat skeletal muscle sarcoplasmic reticulum [20]. Both lipids were purified by preparative thin-layer chromatography.

Purification of the PI-transfer protein I and II. The PI-transfer protein was purified from bovine brain by a modification of published procedures $[3,21]$. Transfer activity was routinely measured with the fluorescent lipid transfer assay as described by Somerharju et al. [17]. Briefly, the purification scheme consisted of the following steps. A $25 \%$ homogenate $(w / v)$ of the cerebral cortex of ten bovine brains $(3.0 \mathrm{~kg}$ wet weight) was prepared in $10 \mathrm{mM}$ Tris- $\mathrm{HCl} / 1 \mathrm{mM}$ EDTA $/ 1$ $\mathrm{mM} \mathrm{PMSF} / 0.9 \% \mathrm{NaCl}$ (pH 7.4). Following centrifugation at $14000 \times g$ for $1 \mathrm{~h}$, ammonium sulfate was added to the supernatant till $70 \%$ saturation. After centrifugation the pellet was resuspended in $5 \mathrm{mM}$ sodium phosphate buffer (pH 7.2). The suspension was extensively dialyzed against the same buffer, and centrifuged overnight $(14000 \times g)$ to remove the microsomes still present. The supernatant was applied to a DEAE-cellulose Whatman DE52) column $(6 \times 80 \mathrm{~cm})$, and eluted with a linear gradient of $0-0.3 \mathrm{M} \mathrm{NaCl}$ in the phosphate buffer. The PI-transfer protein activity, which eluted at approx. $60 \mathrm{mM}$, was collected, concentrated against Aquacide (Calbiochem, type III), and further fractionated on a Sephadex G-75 (Pharmacia) column $(4-160 \mathrm{~cm}$ ) in $5 \mathrm{mM}$ sodium phosphate $/ 5 \mathrm{mM}$ mercaptoethanol $/ 0.01 \%$ sodium azide $(\mathrm{pH} 6.8)$. The active fractions were combined and, after addition of $10 \%$ glycerol, applied on a hydroxyl apatite (BioGel, HTP, Bio-Rad) column $(3 \times 18 \mathrm{~cm})$. The transfer protein was eluted with a linear gradient of $10-100 \mathrm{mM}$ sodium phosphate $10 \%$ glycerol $(\mathrm{v} / \mathrm{v})(\mathrm{pH}$ 6.8). The active fractions which eluted at approx. $50 \mathrm{mM}$ were combined, dialyzed against $10 \mathrm{mM}$ Tris- $\mathrm{HCl}(\mathrm{pH} 7.8)$ and the transfer protein further purified on a Mono $Q$ anion exchange column (FPLC, Pharmacia) by use of a $\mathrm{NaCl}$ gradient $(0-200 \mathrm{mM})$ in $20 \mathrm{mM}$ Tris- $\mathrm{HCl}(\mathrm{pH}$ 7.8). The PI-transfer proteins I and II eluted at 90 and $85 \mathrm{mM} \mathrm{NaCl}$, respectively. The purity of these proteins was checked by sodium dodecyl sulfate polyacrylamide gel electrophoresis and slab gel isoelectric focusing. The PI-transfer protein consisted of form I for approx. 65\% and of form II for $35 \%$. The final yield amounted to $6.5-7.5 \mathrm{mg}$ of transfer protein per $\mathrm{kg}$ cerebral cortex. Both forms displayed a similar specific transfer activity of $340 \mathrm{nmol}$ PI per min per $\mathrm{mg}$ at $37^{\circ} \mathrm{C}$ as established by the microsome-vesicle transfer assay [7].

Preparation of phospholipid vesicles. Vesicles consisting of parinaroyl-PC or parinaroyl-PI were prepared by ethanol injection [22]. Ethanolic solutions $(10 \mu 1)$ of the fluorescent phospholipids $(0.5-4 \mathrm{mM})$ were injected into $2 \mathrm{ml}$ of $20 \mathrm{mM}$ Tris- $\mathrm{HCl} / 5 \mathrm{mM}$ EDTA/ $200 \mathrm{mM} \mathrm{NaCl}$ (pH 7.4). Prior to the experiments the buffers were routinely filtered (0.45 $\mu \mathrm{m}$, Millipore), degassed, and saturated with argon. Vesicles of non-fluorescent 
phospholipids were prepared by ultrasonication of a phospholipid suspension $(2 \mathrm{mM})$ in the TrisEDTA- $\mathrm{NaCl}$ buffer at $0^{\circ} \mathrm{C}$ under a nitrogen atmosphere with a Branson sonifier (50 watts, 10 $\min$ ).

Phospholipid binding assays. The binding of fluorescent phospholipid analogs was studied by titrating a solution of completely quenched donor vesicles consisting of pure parinaroyl-PC or parinaroyl-PI with PI-transfer protein in $20 \mathrm{mM}$ Tris- $\mathrm{HCl}-E D T A-\mathrm{NaCl}$ buffer. The increase in fluorescence resulting from the formation of a PItransfer protein-fluorescent phospholipid complex was taken as a measure for binding [6].

Preparation of the transfer protein-phospholipid complex. Fluorescent and radiolabeled PC and PI were incorporated into the PI-transfer protein by incubating the transfer protein (approx. $40 \mu \mathrm{g} / \mathrm{ml}$ ) for $15 \mathrm{~min}$ at room temperature with phospholipid vesicles consisting of either pure labeled PI or labeled phosphatidylcholine/phosphatidic acid (PC/PA) (70:30 mol\%, approx. $4 \mu \mathrm{m})$ in $20 \mathrm{mM}$ Tris- $\mathrm{HCl} / 50 \mathrm{mM} \mathrm{NaCl} / 5 \mathrm{mM} \mathrm{MgCl}{ }_{2}(\mathrm{pH} \mathrm{7.4})$. After incubation the transfer protein-phospholipid complex was separated from the vesicles by applying the mixtuure to a small DEAE-cellulose column (volume of $1 \mathrm{ml}$ ) equilibrated with the Tris$\mathrm{NaCl}-\mathrm{MgCl}_{2}$ buffer. Under these conditions the negatively charged phospholipid vesicles were completely retained by the column while the protein-lipid complex was recovered for more than $90 \%$ in the void volume with a minimal dilution. Magnesium chloride was added to the buffer to prevent loss of transfer protein due to strong binding to the negatively charged vesicles.

Isoelectric focusing of PI-transfer protein. PItransfer protein I and II were loaded with $\left[{ }^{14} \mathrm{C}\right] \mathrm{PC}$ or $\left[{ }^{3} \mathrm{H}\right] \mathrm{PI}$ and subjected to isoelectric focussing on polyacrylamide slab gel in the presence of $1 \%$ carrier ampholytes (Bio-Rad). Focussing took place for $5 \mathrm{~h}$ at $500 \mathrm{~V}$. Subsequently the gel was stained with Coomassie brilliant blue (R-250, Serva) to visualize the protein bands, or sliced in 2 $\mathrm{mm}$ bands to determine the distribution of radioactivity. The slices were dissolved in $1 \mathrm{ml}$ of Bio-Solve (Beckman), and the radioactivity determined by liquid scintillation counting in Instagel (Packard), with a Packard Tricarb scintillation counter.
Fluorescence measurements. The static fluorescence measurements were carried out as described before using a Perkin-Elmer MPF-3 fluorimeter [16,17]. Excitation and emission wavelengths were set at $324 \mathrm{~nm}$ and $420 \mathrm{~nm}$, respectively, and the excitation and emission slits at 2 and $40 \mathrm{~nm}$, respectively. During the measurements the sample was continuously stirred with a magnetic bar, and the temperature in the thermostated cuvette holder was kept at $25^{\circ} \mathrm{C}$. Whenever required, corrections were made for dilution and for contributions of tryptophan fluorescence. The fluorescence data were not corrected for inner and outer filtering effects since the absorbance at the excitation and emission wavelengths always remained below 0.1 .

The time-resolved fluorescence measurements were performed at $20^{\circ} \mathrm{C}$ with the equipment described in Ref. 23. Excitation was at $306 \mathrm{~nm}$, the emission was viewed through a Balzers K45 band-pass filter, and a HMP'B polaroid sheet was used in the set-up. The fluorescence and anisotropy decays were obtained via a repeated cycle $(10 \mathrm{~s})$ of measuring the parallel $\left(I_{\|}\right)$and perpendicular $\left(I_{\perp}\right)$ fluorescent components. Ten cycles were sufficient for a good signal to noise ratio. Background was taken into account by measuring the fluorescence signal of transfer protein blanks which had undergone the same treatments, only lacking the fluorescent lipids. The 1024 data points of each component were stored in subgroups of a multichannel analyzer (ND66, Nuclear Data). The data were then transferred to the VAX-8600 computer of the Agricultural University, where the data analysis took place. Fluorescence and anisotropy decays were analyzed via a non-linear iterative least-squares procedure [23-25]. Fluorescence decay was analyzed using the following expression

$S(t)=I_{\|}(t)-I_{\|}^{\mathrm{B}}(t)+2\left[I_{\perp}(t)-I_{\perp}^{\mathrm{B}}(t)\right]$

where $I_{\perp}(t)$ and $I_{\| \mid}(t)$ are the time-dependent polarized emission components and the superscript $B$ denotes the components arising from the blank. Appropriate weighting factors were used in the analysis. The total fluorescence $S(t)$ was fitted to a triexponential function of the form:

$S(t)=\alpha_{1} \exp \left(-t / \tau_{1}\right)+\alpha_{2} \exp \left(-t / \tau_{2}\right)+\alpha_{3} \exp \left(-t / \tau_{2}\right)$ 
where $\alpha_{1}, \alpha_{2}$ and $\alpha_{3}$ are preexponential factors belonging to the fluorescence lifetimes $\tau_{1}, \tau_{2}$ and $\tau_{3}$, respectively. The average fluorescence lifetime $\langle\tau\rangle$ is given by:

$\langle\tau\rangle=\alpha_{1} \tau_{1}+\alpha_{2} \tau_{2}+\alpha_{3} \tau_{3}$

For the anisotropy $I_{\|}(t)$ and $I_{\perp}(t)$ were fitted simultaneously to yield the parameters describing anisotropy decay $r(t)$ :

$I_{\| 1}(t)=\frac{S(t)}{3}[1+2 r(t)]$

$I_{\perp}(t)=\frac{S(t)}{3}[1-r(t)]$

\section{Results}

\section{Interconversion of PI-transfer protein I and II}

We established by isoelectric focussing that PItransfer protein I and II have isoelectric points of 5.5 and 5.7 , respectively. In view of the dual specificity of this transfer protein we wondered whether the binding of either PI or PC, could be the cause of this small difference. To test this hypothesis PI-transfer protein II was incubated with $\left[{ }^{14} \mathrm{C}\right] P C$ or $\left[{ }^{3} \mathrm{H}\right] \mathrm{PI}$ vesicles, and the proteinlipid complex isolated as described in Materials and Methods. After concentration against Aquacide a sample containing both complexes was subjected to isoelectric focussing on a polyacrylamide slab gel. As is shown in Fig. 1 the PI-transfer protein II containing $\left[{ }^{3} \mathrm{H}\right] \mathrm{PI}$ was clearly separated from the protein containing $\left[{ }^{14} \mathrm{C}\right] \mathrm{PC}$. The isoelectric points corresponded to 5.5 for the PI-containing transfer protein and 5.7 for the PC-containing transfer protein. To provide further evidence for the interconversion of PI-transfer protein I and II, protein II was incubated with vesicles containing PC or PI, and the isolated lipid-protein complexes subjected to isoelectric focussing (Fig. 2). In this instance the protein bands were visualized by staining with Coomassie brilliant blue. Incubation of PI-transfer protein II with PC did not affect the isoelectric point (lane $\mathrm{A}, \mathrm{p} I 5.7$ ), while subsequent incubation of this lipid-protein complex with PI vesicles resulted in a shift to $\mathrm{p} I 5.5$ (lane B). Alternatively, incubation of transfer protein II and PI vesicles shifted the $\mathrm{p} I$ to 5.5 (lane $\mathrm{C}$ ), while

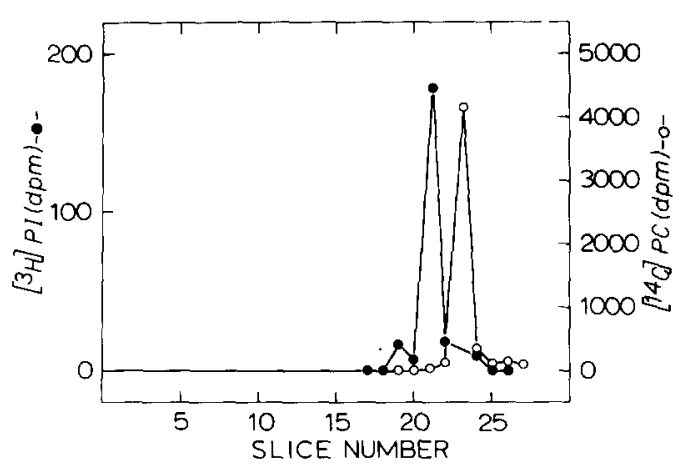

Fig. 1. Polyacrylamide gel isoelectric focussing of isolated PI-transfer protein- $\left[{ }^{14} \mathrm{C}\right] \mathrm{PC}$ and $-\left[{ }^{3} \mathrm{H}\right] \mathrm{PI}$ complexes. PI-transfer protein II was incubated with either $\left[{ }^{14} \mathrm{C}\right] \mathrm{PC}$ (spec. act. $58.5 \mathrm{Ci} / \mathrm{mol}$ ) or $\left[{ }^{3} \mathrm{H}\right] \mathrm{PI}$ (spec. act. $1.8 \mathrm{Ci} / \mathrm{mol}$ ), and the resulting protein-lipid complex was isolated as described in Materials and Methods. After dialysis against $5 \mathrm{mM}$ Tris$\mathrm{HCl} / 1.25 \mathrm{mM}$ EDTA (pH 7.2) the samples were concentrated against Aquacide. 50- $\mu 1$ samples of PI-transfer protein containing $\left[{ }^{14} \mathrm{C}\right] \mathrm{PC}\left(8400 \mathrm{dpm}, 35 \mu \mathrm{g}\right.$ protein) and $\left[{ }^{3} \mathrm{H}\right] \mathrm{PI}(1250 \mathrm{dpm}$, $35 \mu \mathrm{g}$ protein) were mixed, and subjected to isoelectric focussing. After electrophoresis the $\mathrm{pH}$ in the gel was determined with a surface $\mathrm{pH}$ electrode, and by staining part of the gel containing a protein $\mathrm{p} I$ calibration kit (Pharmacia) with Coomassie brilliant blue. Based on this $\mathrm{pH}$ determination the section of the gel between pH 4.5 and 6.0 was sliced into $2 \mathrm{~mm}$ slices, digested in $1 \mathrm{ml}$ Bio-Solve (Beckman) and the radioactivity was measured by liquid scintillation counting. The closed circles represent the ${ }^{3} \mathrm{H}$-, and the open circles the ${ }^{14} \mathrm{C}$-radioactivity.

subsequent incubation with $\mathrm{PC}$ vesicles resulted in a partial recovery of the $\mathrm{p} I 5.7$ band (lane D). This partial recovery agrees with the general notion that the protein has a much higher affinity for PI than for PC. In summary these results clearly indicate that the one charge difference between PI and PC is the cause of the observed shift in isoelectric points between transfer protein I and II.

\section{Specificity of phospholipid binding}

The data in Figs. 1 and 2 strongly suggest that upon isolation from bovine brain PI-transfer protein I contains PI, and PI-transfer protein II PC. Here we have investigated the binding of parinaroyl-PI and parinaroyl-PC to these two forms of the transfer protein. By titrating quenched vesicles containing these phospholipids, with the transfer proteins, an increase of fluorescence was observed, which was taken as a measure for bind- 


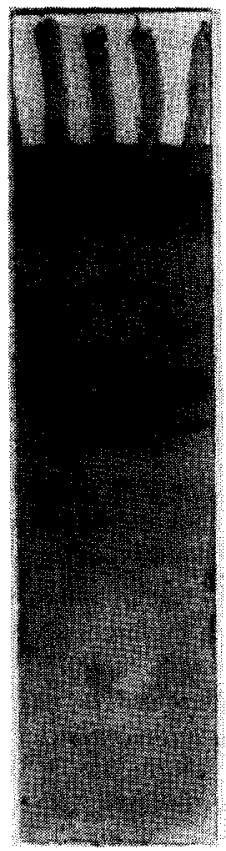

Fig. 2. Interconversion of PI-transfer protein I and II. PI-transfer protein II was incubated with an excess of phospholipid vesicles, and the resulting protein-lipid complex was isolated as described in Materials and Methods. One part of the samples was prepared for isoelectric focussing as before (legend to Fig. 1), while the remainder was again incubated, but now with the other phospholipid. Lane A shows the protein-lipid complex after incubation iwth $\mathrm{PC}$, while lane $\mathrm{B}$ represents the sample after subsequent incubation with PI. Lanes $C$ and $D$ represent the complex after first incubation with PI (C), and after subsequent incubation with PC (D). The positions of the two PI-transfer protein bands correspond with isoelectric points of 5.5 (containing PC) and 5.7 (containing PI), respectively, as compared with the Pharmacia isoelectric focussing calibration kit.

ing [6]. As shown in Fig. 3 protein I and II behave identical in lipid binding, and display both a great preference for PI over PC. Apparently, the presence of endogenous PI or PC on the transfer protein has no effect on the extent to which parinaroyl-PI and parinaroyl-PC are bound. This implies that endogenous PI present on transfer protein I is readily replaced for parinaroyl-PI but very poorly for parinaroyl-PC. Similarly, transfer protein II readily exchanges its endogenous PC for parinaroyl-PI. At this point it is difficult to understand why this endogenous PC is poorly exchanged for parinaroyl-PC. One explanation may be that the transfer protein has a higher affinity

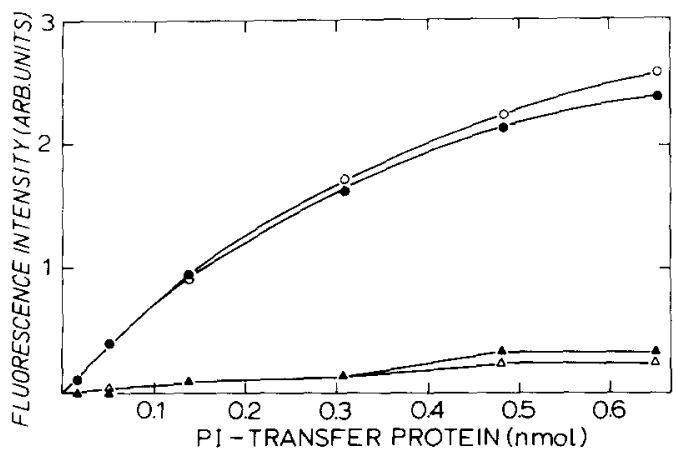

Fig. 3. Binding of fluorescent PC and PI to the PI-transfer protein I and II. Vesicles ( $0.5 \mathrm{nmol}$ lipid) consisting of either 2-parinaroyl-PC $(\Delta, \Delta)$ or 2-parinaroyl-PI $(\mathrm{O}, \bullet)$ in $2 \mathrm{ml} 20$ $\mathrm{mM}$ Tris- $\mathrm{HCl} / 5 \mathrm{mM}$ EDTA $/ 200 \mathrm{mM} \mathrm{NaCl}(\mathrm{pH}$ 7.4) were titrated with PI-transfer protein I $(O, \Delta)$ and II $(\bullet, \Delta)$. The increase in fluorescence is shown as a function of the amount of protein added.

for its endogenous PC species.

The relative quantum yield of the fluorescent PC and PI analogs in the lipid-transfer protein complex were estimated by comparing the fluorescence intensity of the probe in the lipid-protein complex with the intensity of the probe after its release into an egg-yolk PC/yeast PI (9:1, molar ratio) vesicles. Under those conditions we assume a similar fluorescence yield for parinaroyl-PI and $-\mathrm{PC}$ in the vesicle. By this approach it was shown that parinaroyl-PI in the transfer protein has a fluorescence yield similar to that in the phospholipid vesicles, whereas the yield for parinaroylPC in the protein was approx. 40\% lower. Correction for fluorescence yields would raise the curve for PC in Fig. 3, but would not substantially alter the result.

From the above experiments it cannot be concluded whether the PI-transfer protein is able to bind one or more PI molecules. From earlier experiments with monolayers it was estimated that approx. 1.2 molecules of PI were bound per molecule of transfer protein [26]. Here we have determined the number of PI binding sites by titrating single bilayer vesicles of pure parinaroyl-PI with increasing amounts of PI-transfer protein. As shown in Fig. 4 binding of parinaroyl-PI, reflected in an increase of fluorescence, is saturable. This increase is caused by the exchange of the phospholipid molecule bound to the protein for the parinaroyl-PI present in the outer monolayer of 


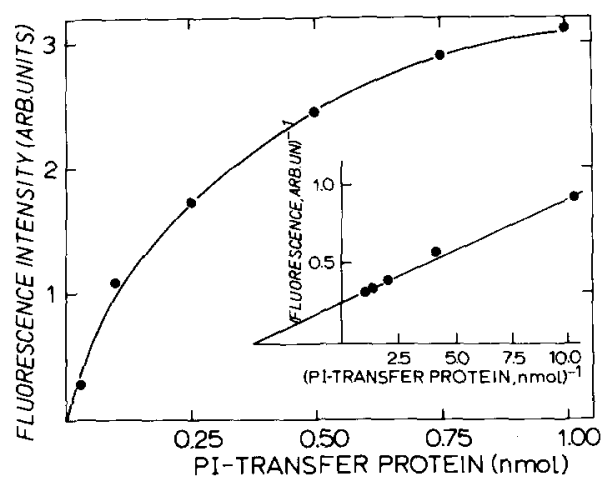

Fig. 4. Estimation of the number of lipid binding sites on the PI-transfer protein from the fluorescent lipid binding curve. Vesicles $(0.5 \mathrm{nmol}$ lipid) consisting of 2-parinaroyl-PI were titrated with PI-transfer protein. Determination of the amount of transfer protein needed to reach half of the maximum fluorescence by way of a double-reciprocal plot (see inset) suggests the presence of one lipid molecule bound per transfer protein molecule.

the vesicles. Assuming a similar binding affinity for the endogenous phospholipid and the fluorescent analog, the half maximal fluorescence increase is reached when the amount of proteinbound phospholipid is equal to the amount of parinaroyl-PI available for exchange. This half maximal value is obtained from the double reciprocal plot of fluorescence increase against transfer protein (inset in Fig. 4). A value of 0.35 nmole was calculated, which agrees with the amount of parinaroyl-PI in the outer monolayer of the vesicles (approx. 70\% of 0.5 nmole). This analysis indicates that the transfer protein has one binding site for PI. As a control we have performed a similar experiment with PC-transfer protein from bovine liver and vesicles of pure parinaroyl-PC. In agreement with earlier reports $[27,28]$ one lipid binding site was observed.

The binding site of parinaroy-PC and parinaroyl-PI

In order to probe the lipid binding site(s) of the PI-transfer protein, parinaroyl-PC and parinaroylPI were incorporated as described in Materials and Methods. For each complex the fluroescence lifetimes and rotational mobility of the 2parinaroyl chain were determined by time resolved fluorescence spectroscopy. As judged from the fitting-criteria [25] a minimum decay model to fit the experimental data consisted of a sum of
TABLE I

TIME-RESOLVED FLUORESCENCE AND ROTATIONAL ANISOTROPY DECAY OF 2-PARINAROYL-PC AND 2-PARINAROYL-PI IN THE PI-TRANSFER PROTEIN

$\Phi$ is the rotational correlation time; $\beta$ is the anisotropy at $t=0$; PI-TP is PI-transfer protein; Pna- is parinaroyl-.

\begin{tabular}{cllll}
\hline Sample & $\alpha$ & $\begin{array}{l}\tau( \pm 0.1) \\
(\mathrm{ns})\end{array}$ & $\beta$ & $\begin{array}{l}\Phi( \pm 0.5) \\
(\mathrm{ns})\end{array}$ \\
\hline Pna-PC/ & 0.40 & 1.3 & 0.31 & 17.4 \\
PI-TP & 0.37 & 5.0 & & \\
& 0.23 & 9.5 & & \\
Pna-PI/ & 0.11 & 1.2 & 0.32 & 16.3 \\
PI-TP & 0.43 & 5.0 & & \\
& 0.46 & 8.6 & & \\
\hline
\end{tabular}

three exponential terms. The fluorescence lifetimes derived from this analysis are presented in Table I. It is evident that for the two lipids the three lifetimes are very similar, but that the fractions of the fluorophores contributing to each lifetime component are different, yielding average lifetimes of $4.6 \mathrm{~ns}$ for parinaroyl-PC and $6.3 \mathrm{~ns}$ for parinaroyl-PI. This may indicate a different en-

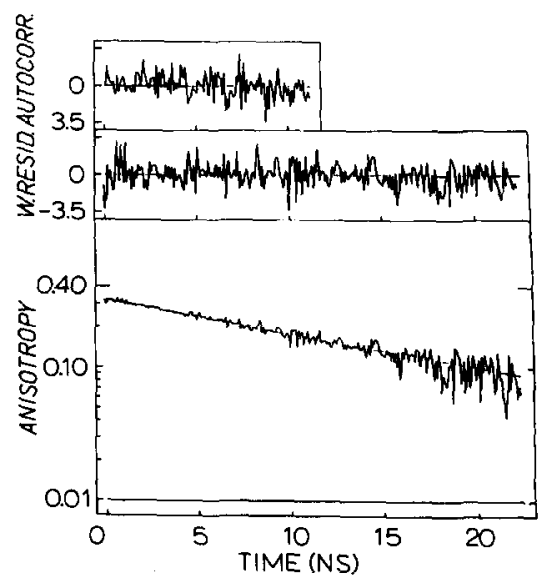

Fig. 5. Fluorescence anisotropy decay of 2-parinaroyl-PI bound to the PI-transfer protein. The experimental anisotropy is represented by the noisy curve, while the smooth line shows the fitted decay function which is a single exponential function. On top of the curves the weighted residuals and the autocorrelation of the residuals are shown. The statistical parameters for this analysis [25] are $\chi^{2}=1.32$ and Durbin Watson parameter $\mathrm{DW}=2.10$. The curve for 2-parinaroyl-PC (not shown) was virtually identical. All parameters $(\beta, \Phi)$ are given in Table $\mathbf{I}$. 
vironment of the parinaroyl-fatty acyl chain for parinaroyl-PC and parinaroyl-PI in the lipid-protein complex.

Analysis of the fluorescence anisotropy decay curves revealed that the dynamic behaviour of the parinaroyl chain in the two phospholipid-transfer protein complexes was virtually identical (Fig. 5). This decay curve was optimally represented by a single-exponential function, yielding for parinaroyl-PI and parinaroyl-PC rotational correlation times of 16.3 and $17.4 \mathrm{~ns}$, respectively (see Table I). Both the high initial anisotropy $(0.32$ and 0.31 for PI and PC, respectively) and the relatively long correlation times indicate that the $s n-2$ fatty acyl chain of PC and PI are tightly bound to the transfer protein. It appears that the fatty acyl chain is completely immobilized in the lipid binding site and rotates as the lipid-protein complex.

\section{Discussion}

In a great variety of tissues examined to date, the PI-transfer protein has been found to occur in two forms [29], with as the most striking difference a variation of about $0.2 \mathrm{pH}$ units in the isoelectric points. The molecular basis of this difference was unclear. PI-transfer protein from bovine brain was shown to consist of two subforms similar in molecular weight, amino acid composition, sensitivity towards heat denaturation, activity and specificity [7,5]. Antibodies raised against the individual subforms were shown to be completely cross-reactive [4]. Apart from the difference in isoelectric point, a slightly different sensitivity towards trypsin-proteolysis was reported [7]. The fact that this transfer protein was shown to be a diffusable lipid-carrier, capable of accommodating either PC or PI in its lipid binding site $[3,4]$ suggested to us that the extra negative charge on the PI molecule as compared to PC could be the cause for the difference in isoelectric points. We, therefore, loaded the transfer protein with either PI or PC, and examined the electrophoretic behaviour of the resulting lipid-protein complex. It was clearly demonstrated that the PI-transfer protein carrying PI (protein I) is slightly more acidic (i.e., $0.2 \mathrm{pH}$ units) than the protein with a PC molecule (protein II). And that the two subofrms of the protein were interconvertable (see Figs. 2 and 3).
Several reports have stated that the PI-transfer protein has a large preference for transferring PI over PC (i.e., approximately 10 -fold faster) $[4,5,28]$, while transfer of other lipid species was either very low (i.e., phosphatidylglycerol and sphingomyelin), or completely absent (i.e., phosphatidylethanolamine, phosphatidylserine, phosphatidic acid and cardiolipin) (Somerharju et al. [6]). Chemical modification of PI indicated that the PI-transfer protein absolutely requires the intact inositol ring for the lipid to be preferentially transferred. Oxidative cleavage of the inositol ring resulted in a 10 -fold decrease of the rate of transfer of the ensuing PI derivatives [6]. However, modification of $P C$ in the phosphocholine headgroup or the glycerol-hydrocarbon region had much less effect on the affinity $[21,26,17]$. These findings suggest that the transfer protein has a highly specific binding site for the phosphorylinositol headgroup, and a less specific binding site for the phosphorylcholine headgroup.

In the present study lipid-binding specificity was measured with both PI-transfer protein I and II. It was shown that the PI-transfer protein binds PI much more efficiently than PC regardless of whether the protein contains endogenous PI or PC. This preferential binding of PI reflects the high affinity of the transfer protein for this phospholipid class. The ineffective binding of parinaroyl-PC by the transfer protein containing $\mathrm{PI}$ as the endogenous lipid (protein I) is in agreement with this explanation (Fig. 2). The limited ability of the transfer protein II to exchange its endogenous PC molecule for a fluorescent parinaroyl-PC molecule cannot be explained by the low affinity for this phospholipid class. The fluorescent PC analog employed in this study contained cisparinaric acid, a polyunsaturated fatty acid with a rigid conjugated polyene chain, which closely resembles an extended saturated fatty acyl chain [30]. In view of the relatively fast transfer of unsaturated species of $\mathrm{PC}$ [31] we consider it likely that upon isolation PC bound to the PI-transfer protein is unsaturated. The poor binding of parinaroyl-PC may be due to the high affinity of the PI-transfer protein for its endogenous unsaturated PC species. The phospholipid monolayer technique has been used to determine the rate at which PI or PC bound to the transfer protein was 
exchanged for a phospholipid molecule from the monolayer [26]. It was established that under a monolayer of PI the protein-bound PC was exchanged approximately seven times faster than the endogenous PI. With monolayers of PC, exchange of both endogenous PI and PC was extremely slow. These rate measurements clearly demonstrated the great preference of the transfer protein for PI over PC. Since the transfer protein exchanges its endogenous phospholipid much faster with vesicles, the data presented here refer to equilibrium values, and give no information on the rates of exchange.

An important question in understanding the mode of action of the PI-transfer protein is the spatial relationship between the binding sites for PI and PC. Studies with phospholipid monolayers have indicated that binding of PI and PC are mutually exclusive. It has been proposed that the PI-transfer protein might have one common site for the accommodation of the acyl chains of PI and PC $[5,6]$.

Time-resolved fluorescence measurements have demonstrated that the 2-parinaroyl chain of PI and $P C$ are completely immobilized when bound to the protein, but that the average fluorescence lifetimes are significantly different (4.6 ns for PC and $6.3 \mathrm{~ns}$ for $\mathrm{PI})$. The average lifetime is probably related to the polarity of the binding site for the 2-acyl chain, which has a large influence on the actual lifetime value [32,33]. The complete immobilization of the 2-acyl chain in both phospholipids, evidenced by a long-lived anisotropy decay, indicates an efficient binding to a hydrophobic pocket on the protein. However, the difference in average fluorescence lifetime shows that the local environment of the chromophores in the two lipids is different. This could mean that the two acyl chains for PI and PC have different binding sites. Another possibility could be that the 2-acyl chains of PI and PC share a common hydrophobic binding site in which they are differently oriented causing environmental microheterogeneity. The slightly different values for the rotational correlation times (17.4 ns and $16.2 \mathrm{~ns}$ for PC and PI, respectively) favour the latter possibility. We cannot rule out the possibility that the difference is caused by the difference in charge of the two lipid-protein complexes. Parinaroyl-PC bound to the PC-transfer protein from bovine liver was also completely immobilized, having a rotational correlation time of $11 \mathrm{~ns}$ [14]. The longer correlation times measured for the PI-transfer protein reflect the higher molecular weight. A correlation time of $15.9 \mathrm{~ns}$ is characteristic for a spherical protein with a molecular weight of 35000 [34]. This agrees with the molecular weight of the PItransfer protein determined with sodium dodecyl sulfate gel electrophoresis $(33000)[7,3]$.

From steady-state fluorescence measurements we could determine that the fluorescence yield of 2-parinaroyl-PC in the PI-transfer protein is approximately $40 \%$ lower than that of 2-parinaroylPI. This difference is also reflected in the longer average fluorescence lifetime for PI (i.e., $6.3 \mathrm{~ns}$ for $\mathrm{PI}$ and $4.6 \mathrm{~ns}$ for PC). 2-Parinaroyl-PC in the PC-transfer protein from bovine liver has an average lifetime of $2.5 \mathrm{~ns}$ [14]. This strongly suggests that the binding site for the 2-acyl chain on the PI-transfer protein is more hydrophobic than on the PC-transfer protein. This difference in polarity may explain why the fluorescence yield for parinaroyl-PI in the PI-transfer protein and in vesicles is very similar, whereas the fluorescence yield for 2-parinaroyl-PC in the PC-transfer protein is 5-times lower than in vesicles.

From the results presented here it can be concluded that the PI-transfer proteins I and II are actually the same protein carrying different phospholipids. Upon isolation from bovine brain approx. $65 \%$ of the protein carries a PI molecule, which, in view of the much higher PC content in the cell, indicates a high preference for PI. Although this protein can transfer PC very well under artificial assay conditions, it apepars that inside the cell the major part of the transfer protein is engaged in PI binding and transfer. Further research should clarify the role of this protein in intracellular PI metabolism.

\section{Acknowledgments}

We are most grateful to Dr. P.J. Somerharju for his advice and stimulating discussions and to $\mathrm{A}$. van Hoek for the excellent technical assistance with the time-resolved fluorescence measurements. 


\section{References}

1 Wirtz, K.W.A. (1982) in Lipid-Protein Interactions (Jost, P.C. and Griffith, O.H., eds.), Vol. 1, pp. 151-231, WileyInterscience, New York

2 Demel, R.A., Somerharju, P. and Wirtz, K.W.A. (1985) in Phospholipids in the Nervous System (Horrocks, L.A., Kanfer, J.N. and Porcellati, G., eds.), Vol. 2, pp. 61-70, Raven Press, New York

3 Demel, R.A., Kalsbeek, R., Wirtz, K.W.A. and Van Deenen, L.L.M. (1977) Biochim. Biophys. Acta 466, 10-22

4 Helmkamp, G.M., Wirtz, K.W.A. and Van Deenen, L.L.M. (1976) Biochim. Biophys. Acta 174, 592-602

5 DiCorleto, P.E., Warach, J.B. and Zilversmit, D.B. (1979) J. Biol. Chem. 254, 7795-7802

6 Somerharju, P., Van Paridon, P. and Wirtz, K.W.A. (1983) Biochim. Biophys. Acta 731, 186-195

7 Helmkamp, G.M., Harvey, M.S., Wirtz, K.W.A. and Van Deenen, L.L.M. (1974) J. Biol. Chem. 249, 6382-6389

8 Lumb, R.H., Kloosterman, A.D., Wirtz, K.W.A. and Van Deenen, L.L.M. (1976) Eur. J. Biochem. 69, 15-22

9 Daum, G. and Paltauf, F. (1984) Biochim. Biophys. Acta 794, 385-391

10 George, P.Y, and Helmkamp, G.M. (1985) Biochim. Biophys. Acta 836, 176-184

11 Helmkamp, G.M., Nelemans, S.A. and Wirtz, K.W.A. (1976) Biochim. Biophys. Acta 424, 168-182

12 Sklar, L.A., Hudson, B.S. and Simoni, R.D. (1977) Biochemistry $16,5100-5108$

13 Wolber, P.K. and Hudson, B.S. (1981) Biochemistry 20 , 2800-2810

14 Berkhout, T.A., Visser, A.J.W.G. and Wirtz, K.W.A. (1984) Biochemistry 23, 1505-1513

15 Tevelyan, W.G. (1966) J. Lipid Res. 7, 445-447

16 Somerharju, P. and Wirtz, K.W.A. (1982) Chem. Phys. Lipids 30, 81-91
17 Somerharju, P., Brockerhoff, H. and Wirtz, K.W.A. (1981) Biochim. Biophys. Acta 649, 521-528

18 Somerharju, P.J., Virtanen, J.A., Eklund, K.K., Vainio, P. and Kikkunen, P.K.J. (1985) Biochemistry 24, 2773-2781

19 Stoffel, W., Le Kim, D. and Tschung, T.S. (1972) HoppeSeyler's Z. Physiol. Chem. 352, 1052-1064

20 Shute, J.K. and Smith, M.E. (1984) Biochem. J. 222, 299-305

21 Demel, R.A., Van Bergen, B.G.M., Van den Eeden, A.L.G., Zborowski, J, and Defize, L.H.K. (1982) Biochim. Biophys. Acta 710, 264-270

22 Batzri, S. and Korn, E.D. (1973) Biochim. Biophys. Acta 298, 1015-1019

23 Van Hoek, A., Vervoort, J. and Visser, A.J.W.G. (1983) J. Biochem. Biophys. Methods 7, 243-254

24 Visser, A.J.W.G. (1982) Biochim. Biophys. Acta 692, 244-251

25 Visser, A.J.W.G., Ykema, T., Van Hoek, A., O'Kane, D.J. and Lee, J. (1985) Biochemistry 24, 1489-1496

26 Zborowski, J. and Demel, R.A. (1985) Chem. Phys. Lipids $38,3-16$

27 Kamp, H.H., Wirtz, K.W.A. and Van Deenen, L.L.M. (1973) Biochim. Biophys. Acta 318, 313-325

28 Demel, R.A., Wirtz, K.W.A., Kamp, H.H., Geurts van Kessel, W.S.M. and Van Deenen, L.L.M. (1973) Nature (London) New Biol. 246, 102-105

29 Helmkamp, G.M. (1985) Chem. Phys. Lipids 38, 3-16

30 Sklar, L.A., Hudson, B.S. and Simoni, R.D. (1975) Proc. Natl. Acad. Sci. USA 72, 1649-1653

31 Helmkamp, G.M. (1980) Biochemistry 19, 2050-2056

32 Sklar, L.A., Hudson, B.S., Petersen, M. and Diamond, J. (1977) Biochemistry 16, 813-818

33 Parasassi, T., Conti, F. and Gratton, E. (1984) Biochemistry $23,5660-5664$

34 Visser, A.J.W.G. and Lee, J. (1982) Biochemistry 21, $2218-2226$ 